\title{
Highs and lows in motor control development
}

Marie Martel $^{1,2^{*}}$, Pierre Fourneret ${ }^{3,2}$, Livio Finos ${ }^{4}$, Christina Schmitz ${ }^{5,2}$, Alice Catherine Roy ${ }^{1}$

1 Laboratoire Dynamique Du Langage, CNRS UMR5596, Université Lyon 2, Université de Lyon, Lyon, France 2 Université Claude Bernard Lyon 1, Université de Lyon, Lyon, France

3 Institut des Sciences Cognitives Marc Jeannerod, CNRS UMR5304 ; Service de Psychopathologie du Développement, Hôpital Femme-Mère-Enfant, Hospices Civils de Lyon, Bron, France

4 Department of Statistical Sciences, University of Padova, Italy

5 Lyon Neuroscience Research Center, Brain Dynamics and Cognition team, INSERM UMRS 1028, CNRS

UMR 5292, Université Claude Bernard Lyon 1, Université de Lyon, Lyon, France

\section{Corresponding author:}

Marie Martel

marie.martel@isc.cnrs.fr 
Abstract: Motor control is classically described as relying on two components: anticipatory control (feedforward processing) and online control (feedback processing). Here we aimed to unveil the developmental steps of both feedback and feedforward control in 5 to 10 years old children, using a simple and ecological task. We manipulated object's weight in a reach-to-displace paradigm. When the weight was known before lifting it, anticipatory processes were quantifiable during the reaching phase. Conversely, an unknown weight triggered online corrections during the displacing phase. Movement kinematics revealed that children anticipate this objet property as young as $5 \mathrm{y}-\mathrm{o}$. This anticipation becomes adequate around $7 \mathrm{y}-\mathrm{o}$ and is paralleled by poor online corrections. This simple yet relevant paradigm should allow quantifying deviations from neurotypical patterns in disorders of motor control.

Keywords: reach-and-grasp, anticipatory control, online control, children, motor development, kinematics 


\section{Introduction}

Motor control is classically described as relying on two components: the anticipatory control based on a feedforward processing and the online control based on a feedback processing. When reaching for an object, the feedforward control computes its shape, texture, weight, size (but see Smeets \& Brenner, 1999 for an alternative view), spatial location and distance from the body and uses this information to build a motor program anticipating the object properties (Ansuini et al., 2016; Ansuini, Giosa, Turella, Altoè, \& Castiello, 2008; Becchio et al., 2014; Cashaback, McGregor, Pun, Buckingham, \& Gribble, 2017; Gentilucci, 2002). However, because residual errors remain in the motor program or because the object properties might change unexpectedly, feedback processing comes into play to correct online actions and reach the desired goal (Buckingham, Ranger, \& Goodale, 2011). Such movement preparation and execution imply multisensory integration of both visual and proprioceptive information from the body and the environment (Sober \& Sabes, 2003; Zhang, Brenner, Duysens, Verschueren, $\&$ Smeets, 2018). Through the emergence of internal models, the last decades have seen the refinement of the concept of online control that is better described as a comparison between a predicted feedback built from a forward model and the proper sensory feedback processing (see Desmurget \& Grafton, 2000 for a review).

Anticipation and online control have been mainly described through kinematic profiling of reach and grasp movements in adults (see for example Ansuini et al., 2015; Jeannerod, 1984; Sarlegna \& Mutha, 2015). However, their interplay has been scarcely investigated during development. As the need for identifying specific motor patterns in developmental pathologies such as Autistic Spectrum Disorder and Developmental Coordination Disorder grows (Ansuini, Podda, Battaglia, Veneselli, \& Becchio, 2018; Sumner, Leonard, \& Hill, 2016), it becomes crucial to determine the normal developmental milestones of feedforward and feedback modes of control. Overall, starting with a high movement variability at 5-6 year of age, children around 10 yo reach an adult-like (though still different) control of prehension (Schneiberg, Sveistrup, McFadyen, McKinley, \& Levin, 2002; Smyth, Anderson, \& Churchill, 2001), going through a transition period between 7 and 8 (Hay, 1978; Hay, Bard, Ferrel, Olivier, \& Fleury, 2005; Hay, Fleury, Bard, \& Teasdale, 1994; Pellizzer \& Hauert, 1996; Smyth, Katamba, \& Peacock, 2004; Smyth, Peacock, \& Katamba, 2004). Previous studies have mainly focused on visual information processing and eventually agreed on a protracted development of motor control, however visual and proprioceptive information are both critical to motor control (Ernst \& Banks, 2002; Sober \& Sabes, 2003). Most importantly, 
as will be detailed below, feedforward and feedback control development appears to display different maturation rates, whether authors focused on vision, or haptic information (e.g. Contreras-Vidal, Bo, Boudreau, \& Clark, 2005; Konczak, Jansen-Osmann, \& Kalveram, 2003). The balance between visual and proprioceptive information indeed evolves during development and appears to be statistically adult-like between 8 and 10 years old (Gori, Del Viva, Sandini, \& Burr, 2008; Nardini, Begus, \& Mareschal, 2013; Nardini, Jones, Bedford, \& Braddick, 2008), an age that seems crucial in the maturation of motor control.

In both children and adults, a well-established way to probe the reliance on feedback versus feedforward processing consists in removing the visual information. Performing an accurate movement without visual feedback is thought to highlight the use of feedforward control. Indeed, when reaching in the dark, the movement cannot be corrected online on the basis of visual information; this implies anticipating the characteristics of the movement based, for example, on previous reaches when vision was available. Consequently, the differences typically observed between reaches performed without, as compared to with visual feedback, are taken to reflect the activity of feedforward control (Desmurget \& Grafton, 2000). The correct development and use of a trustworthy internal representation of the reaching movement to be performed enable children to perform a movement without visual feedback. In children aged 4 to 6 , the lack of difference between movements with and without visual feedback has been interpreted as reflecting a mature feedforward control (Hay, 1978; Smyth, Katamba, et al., 2004). However, these paradigms consisted in removing the vision of the hand. An absence of difference between movement with and without vision of the hand could reveal the use of a proprioceptive feedback rather than a visual one regarding hand position, thus limiting the interpretation of a mature feedforward control. Zoia and colleagues reported a correct grip scaling in a similar no-vision condition in children as young as 5 (Zoia et al., 2006). Nevertheless, the anticipatory control for precision grip based on visual characteristics emerges particularly early during infancy (Berthier \& Carrico, 2010) and as such, might not represent a valuable test of the feedforward control maturity. Sarlegna and collaborators suggested that the visual input of the hand might contribute to online control to a lesser extent, as compared to the vision of the target (Sarlegna et al., 2003; see also Saunders \& Knill, 2004; Sarlegna \& Mutha, 2015 for review). Babinsky and colleagues (Babinsky, Braddick, \& Atkinson, 2012), indeed, reported that 4- to 5-yo children successfully reached their target in only $58 \%$ of movements when vision of both the hand and the target were concealed, suggesting an immature feedforward control. Other authors stressed that children aged 6 
extensively relied on visual feedback, as compared to adults (Kuhtz-Buschbeck, Stolze, Boczek-Funcke, et al., 1998; Kuhtz-Buschbeck, Stolze, Jöhnk, Boczek-Funcke, \& Illert, 1998). To sum up, previous studies evaluating prehension consistently reported that young children rely on feedback processing, as their feedforward control may not be fully functional yet.

A fruitful way to unveil the contribution of feedback processing in human and non human primates is the prehension perturbation paradigm (Farnè et al., 2003; Flash \& Henis, 1991; Roy, Paulignan, Meunier, \& Boussaoud, 2006). In these paradigms, a target property (e.g position: Brenner \& Smeets, 1997; Paulignan, MacKenzie, Marteniuk, \& Jeannerod, 1991; orientation: Desmurget et al., 1996; Gréa, Desmurget, \& Prablanc, 2000; Voudouris, Smeets, \& Brenner, 201; size: Castiello, Bennett, \& Stelmach, 1993; Paulignan et al., 1991) is changed at the very beginning of the movement (Sarlegna, 2006). As the sensory information are being continuously monitored, the movement is rapidly corrected when perturbed to face the new target characteristics. Depending on the targeted object property (Veerman, Brenner, $\&$ Smeets, 2008), the first correction may be seen as early as $100 \mathrm{~ms}$ after the movement onset (on the acceleration profile, see Paulignan et al., 1991). Few perturbation studies in reach-tograsp movements have examined feedback processing during development. They revealed a reliable feedback processing during childhood (Hyde \& Wilson, 2011a, 2011b; Plumb et al., 2008), nevertheless children between 8 and 12 years are capable of earlier corrections as compared to 6-7 years old (Wilson \& Hyde, 2013).

In addition, feedforward and feedback controls have been investigated through proprioception and haptic sense by varying the object weight. Numerous studies in adults have shown that the mass of an object affects grasp kinematics prior-to-contact. Lifting a heavy object requires greater forces. Hence, the heavier the object, the longer it takes to exert the appropriate force (Eastough \& Edwards, 2006; Johansson \& Westling, 1984, 1988; Weir, MacKenzie, Marteniuk, Cargoe, \& Frazer, 1991; Westling \& Johansson, 1984). Appropriate fingertips force may be scaled before somatosensory feedback are received thanks to an internal representation of object properties (Gachoud, Mounoud, Hauert, \& Viviani, 1983; Salimi, Hollender, Frazier, \& Gordon, 2000). Through feedback integration, consecutives lifts of the same object sharpen the motor representation of the object, thus tuning the feedforward control (Gordon, Forssberg, Johansson, \& Westling, 1991a; Gordon, Westling, Cole, \& Johansson, 1993; Johansson \& Westling, 1988; Schmitz, Jenmalm, Ehrsson, \& Forssberg, 
2005). As a result, false expectations regarding the weight of the object affect the time elapsed between the end of the reach and the beginning of the lift (Brenner \& Smeets, 1996; Brouwer, Georgiou, Glover, \& Castiello, 2006; Gordon, Forssberg, Johansson, \& Westling, 1991b).

More relevant to this study, kinematics of the reach phase are also affected: when reaching for a heavy object, adults reach faster (with higher amplitudes and shorter latencies, in order to compensate for the consequences of the weight once the object in hand (Roy et al., 2013). Only a few studies have tried to address the issue of feedforward and feedback control through haptic information in children. In this case, the anticipatory control of grip force requires more or less a decade to reach a mature adult-like coordination, scaling capacities based on haptic information being still partially immature around 4-6 years old (Forssberg, Eliasson, Kinoshita, Johansson, \& Westling, 1991; Forssberg et al., 1992; Roy et al., 2013). Gachoud and coworkers (Gachoud et al., 1983) also observed that the representation of object size/weight co-variation was still not developed fully in 9 yo children.

Here we intended to characterize the neurotypical developmental milestones of haptic feedback and feedforward control. Moreover, we aimed at developing a paradigm that would be suitable for the study of motor control in neurodevelopmental disorders. We thus devised an ecological task that does not tax the visual system in a condition more than in another. In addition, this task allows to probe both feedforward and feedback control, without leading to a potential temporal overlap between the two (see Desmurget \& Grafton, 2003). To this end, we manipulated the object weight, a non-visible property of the object, and the knowledge the child had about the object weight before starting to reach it (Flanagan, King, Wolpert, \& Johansson, 2001; Gordon et al., 1993; Hermsdörfer, Li, Randerath, Goldenberg, \& Eidenmüller, 2011; Johansson \& Westling, 1988). The task involved a two-phase action: 1) to reach and grasp an opaque bottle and 2) to displace it to a new location. When the weight was known, the first phase of the movement was informative on feedforward control. Indeed, when the object weight was known in advance, participants had the opportunity to adapt their first phase (Reach) as a function of the expected weight, well before any physical contact with the object. In such "known weight" condition, we could assess the integration and use of (previous) weight information for feedforward control of the first phase (Reach).

Complementarily, when the object's weight was unknown, the second phase of the movement was informative regarding feedback processing. Indeed, when the object weight was unknown (the visual aspect of the object being the same whatever the object weight), participants could adapt to the weight only during the displace phase, through somatosensory feedback 
processing. In such "unknown weight" condition, the kinematic consequences of the weight can only affect the displacement phase, reflecting the online control through somatosensory feedback. In the light of previous work, we hypothesized feedback processing would be faster for oldest children (Wilson \& Hyde, 2013). As for the feedforward control based on haptic characteristics, earlier studies reported traces of feedforward control as early as age 5 (Forssberg et al., 1992; Konczak et al., 2003). We further hypothesized that 7 to 10 years old would have a (qualitative) adult-like feedforward control, and would thus reach faster for a heavy weight as compared to a light one (Roy et al., 2013).

\section{Material and methods}

\subsection{Participants}

Thirty typically developing children aged from 5 years 1 month to 10 years 7 months old were recruited (mean age $\pm \mathrm{SD}=7$ years 11 months \pm 1 year 9 month; 16 girls). Three groups of ten children each were constituted according to their age: 5 - to 6-year-old (mean age $\pm \mathrm{SD}=5$ years 10 months \pm 6 months; 4 girls; termed hereafter the 5/6 group), 7 - to 8-year-old (mean age $\pm \mathrm{SD}=8$ year 1 month \pm 5 months; 7 girls; termed hereafter the 7/8 group), and 9- to 10year-old (mean age $\pm \mathrm{SD}=9$ year 11 months \pm 7 months; 5 girls; termed hereafter the $9 / 10$ group). All were naïve to the purpose of the study, right-handed and had normal or correctedto-normal vision. None of them presented with known neurological disorders, learning disabilities or delayed psychomotor or language acquisition. This study was carried out in accordance with the recommendations of the local ethic committee (CPP Sud-Est II) with written informed consent from all parents. All parents gave written informed consent in accordance with the Declaration of Helsinki, and children gave their assent. The protocol was approved by the Comité de Protection des Personnes (CPP) Sud-Est II. Children received a toy or a board game at the end of the experiment.

\subsection{Apparatus}

Participants were comfortably seated in a quiet room in front of a table; the height of the chair was adapted for each child and a footrest was provided when necessary to ensure an optimal posture. On the table, there was one of two opaque bottles, located at $25 \mathrm{~cm}$ of distance in front of the participants' midline. A predefined marked position was located fifteen centimeters on the right of the bottle in the frontal plane. The bottles were visually identical ( $250 \mathrm{~mL}$ containers) of two different weights. One bottle, termed hereafter "light" was filled 
with sand to obtain a light weight (5- to 6-year-old: $25 \mathrm{~g}$ - 7-to 10-year-old: $50 \mathrm{~g}$ ) and the other bottle, termed hereafter "heavy" was filled with more sand and metallic pieces to obtain a heavy bottle (5- to 6-year-old: $200 \mathrm{~g}$ - 7-to 10-year-old: 500g). The experimental set-up has been described in detail elsewhere (Roy et al., 2013). Prior to the experiment, participants were asked to familiarize themselves with the target objects. Participants were encouraged to verbally characterize the weight differences between the bottles.

\subsection{Experimental procedure}

Participants had to keep their right hand in a pinch grip position on a starting point placed on the edge of the table on their sagittal axis; the non-dominant left hand was kept under the table on the ipsilateral thigh. Upon hearing an acoustic Go signal, children had to grasp the target object at a comfortable speed between the thumb and the index fingers of their right hand and displace it to the predefined location. Children were told to grasp the bottle on its blue cap to ensure a uniformly sized grasp surface $(40 \mathrm{~mm})$ across subjects. At the end of each trial, the participant went back to the starting position and waited for the next trial to begin.

Two conditions were assessed:

- Known object weight: children performed 30 trials: 15 successive trials with each bottle, its weight being counterbalanced between subjects. We chose a block-paradigm in the known condition to ensure the measurement of the most accurate anticipatory performance the child was capable of, that is a feedforward based on stabilized internal representation (Chouinard, 2005)

- Unknown object weight: children performed 30 trials, heavy and light trials $(\mathrm{n}=15$ each) were presented in a pseudo random order. To ensure that participants were unaware of the object weight, the experimenter's manipulation of the bottle was concealed from their view.

The order of the two conditions (known and then unknown) was kept the same for all children, as we wanted to ensure that children had enough experience with the two bottles and their different weights before performing the Unknown object weight condition.

Each movement consisted of two phases. During the Reach phase (reaching \& grasping the bottle), subjects had no contact with the bottle and could only use their internal representation of it to plan the movement (since the visual information was even in all conditions). During 
the Displace phase (lifting \& moving the grasped bottle), the object's weight can influence the movement online.

\subsection{Movement recordings and analysis}

The position of eight active infrared markers was recorded via an Optotrak 3020 system (Northern Digital INC). Three markers were placed on the subject's right hand: on the wrist at the styloid process of the radius, on the nail of the thumb and on the nail of the index (sampling rate at $300 \mathrm{~Hz}$; spatial resolution: $0.1 \mathrm{~mm}$ ). Two markers were positioned on the bottles and the remaining three on the table to define the 3D workspace. Data pre-processing consisted in applying a second-order Butterworth dual pass filter (cutoff frequency: 10Hz). Kinematic parameters were assessed for each trial individually via Optodisp software (Optodisp - copyright INSERM-CNRS-UCBL, (Thévenet, Paulignan, \& Prablanc, 2001). For each movement we measured the whole movement time as the time between the beginning of the hand movement and the moment when the bottle was put in its landing position. We measured the latency and amplitude of the highest wrist acceleration, velocity and deceleration peaks for each movement phase. In addition, for the Reach phase we measured the amplitude and latency of the maximum grip aperture and for the Displace phase, the maximal height at which the bottle was lifted. Parameters as recorded from a single trial are illustrated in figure 1.

\section{**Place figure 1 around here**}

To evaluate the finest motor response to a known and unknown object weight, statistical analyses were performed on the last 8 trials per weight and condition. Trials in which two or more parameters presented values $\pm 2.5 \mathrm{SD}$ (for each condition) were discarded (4.7\%). Analyses were performed with "R" (R Core Team, 2018) and missing values were ignored. To test the combined effect of all measured parameters of the movement a multivariate approach was applied using a resampling-based non parametric MANOVA with Fisher combination of the p-values (Basso \& Finos, 2012; Pesarin, 2001). This allows obtaining a global p-value combining all the parameters of interest in each group, to assess whether children globally acted differently when they knew the weight, and as a function of this weight. This analysis was based on mixed model analyses, but does not give indication of the presence of an interaction between groups. Hence, we also performed mixed model analyses on subjects' individual trials for each kinematic parameter. In terms of interpretation, linear mixed models are similar to ANOVAs, but more adequate for our study as they account for 
relatively small sample size with (relatively high) variability (Boisgontier \& Cheval, 2016). Specifically, we examined the effects of Knowledge, Weight, Group, and their interactions (fixed effects), as well as the intra and inter-individual variability of weight and knowledge effect (random effects). We used lme4 and lmerTest packages. We will mainly focus our analysis on Knowledge X Weight X Group interactions. Indeed, as we hypothesized that both feedforward and feedback control develop with age, we expect such triple interactions to be observed between specific groups. Regarding feedforward control, previous work has shown some traces of feedforward control as early as age 5 and a more mature one around 8 years old. We thus expect triple interactions on Reach phase kinematic parameters between the 5-6year-old children and both older groups. A lack of interaction here would indicate that, contrary to our hypotheses, feedforward control is already mature at 5. Instead, we expected no triple interaction between the two older groups. Any interaction would indicate that despite what is observed in the literature, 7-8-year-old children have a less mature feedforward control than 9-10-year-old children. Regarding feedback control, previous studies have shown good feedback control early in age, but with increased efficiency until 12. We thus hypothesized interactions between each group on their Displace phase kinematics parameters, suggesting that performance improved with age (i.e. decreasing effect of the weight on the movement). Absence of interaction would falsify our hypothesis by indicating similar performance between two groups

\section{Results}

The non parametric MANOVA performed showed that the within factors Weight and Knowledge interacted in each group $(9 / 10$ yo: $F=45.86 ; p=.002 ; 7 / 8$ yo: $F=50.06 ; p=.009$; 5/6 yo: $\mathrm{F}=49.93 ; \mathrm{p}=.001)$. Mixed models on each parameter allowed us to unfold motor strategies in each group, and more importantly, their interaction.

\subsection{Reach phase}

When the object weight was unknown, the Reach phase was similar among the three groups and did not reliably differ as a function of object weight (Figure 2, dashed bars). By contrast, when the object weight was known, all three groups of children displayed effects of the object weight on their Reach phase, before any contact with the object (Figure 2, solid bars). However, the way object weight was anticipated differed between the youngest and the two 
older groups. The two oldest groups anticipated a heavy object by fastening their Reach phase, while the youngest group slowed down their Reach phase when approaching the heavy object.

\section{**Place figure 2 around here**}

Interactions Knowledge *Weight * Group were significant between the 5/6 group and the 7/8 group (acceleration, velocity and deceleration amplitudes, deceleration latency; all $\mathrm{p}<.03$; see Table 1), and between the 5/6 group and the 9/10 group (acceleration, velocity and deceleration amplitudes, deceleration latency and maximum grip aperture; all $\mathrm{p}<.01$ ). Noticeably, the 7/8 and 9/10 groups did not differ in their anticipation of a known object weight, as only one interaction, on the maximum grip aperture $(\mathrm{SE}=2.2, \mathrm{t}=-2.0, \mathrm{p}=.045)$, distinguished their Reach phase.

Specifically (see Table 2 for means and statistics), when reaching for a known heavy object, 7- to 10-year-old children increased their amplitudes and/or decreased their latencies (Figure $\&$ table 2; For the 7/8 group: acceleration and velocity amplitudes; velocity and deceleration latencies. For the 9/10 group: acceleration, velocity and deceleration amplitudes). In addition, for a heavy known weight the 7/8 group tended to open their fingers less (light: 88.2 $\mathrm{mm}$, heavy: $86.1 \mathrm{~mm}, \mathrm{SE}=1.40, \mathrm{t}=1.98, \mathrm{p}=.054$ ), and earlier than for a light object (light: 562 ms, heavy: $508 \mathrm{~ms}, \mathrm{SE}=19.3, \mathrm{t}=2.5, \mathrm{p}=.013$ ). In sharp contrast, the youngest children exhibited the opposite pattern on the wrist profile that is, they decreased their amplitudes and increased their latencies when reaching for a known heavy object (Figure $2 \&$ table 2).

\section{**Place figure 3 around here**}

\subsection{Displace phase}

Once the object in hand, significant triple interactions Knowledge ${ }^{*}$ Weight ${ }^{*}$ Group were observed. The $5 / 6$ group differed from the 7/8 group on 5 out of 7 parameters (acceleration latency, acceleration, velocity and deceleration amplitudes and height; all ps $<.040$ ) and from the $9 / 10$ on 3 parameters (acceleration, velocity and deceleration amplitudes; all $\mathrm{p}<.024$ ). These interactions suggested that when the weight was unknown it affected less the behavior of the youngest children as compared to the other two groups (see tables 1 and 3 for means 
and statistics; Figures $4 \mathrm{a}$ and $4 \mathrm{~b}$ ). This could suggest that the 5/6 group had a better feedback control than older children. Interestingly, the 5/6 group did not interact with the 9/10 group on the last parameter of the movement, that is the height of the bottle $(\mathrm{SE}=6.27, \mathrm{t}=1.36, \mathrm{p}=$ .174). While the weight effect lasted until the very last parameter of the movement for the $7 / 8$ group when the weight was previously known, both 5/6 and 9/10 did not modulate their deceleration amplitude or height: this result suggests that at the end of the movement, these two groups had fully overcome the weight effect. Note however, that two factors blurred the comparison between the 5/6 and other two groups and could thus have influenced such interactions. First, the 5/6 group grasped an object which was lighter than the one grasped by the older children. Second, the Reach phase, known to influence the Displace phase (Roy et al, 2013), was different between the younger children and the other two groups.

More relevant to our purpose are the significant triple interaction we observed (on 4 out of 7 parameters) between the 7/8 and the 9/10 group (acceleration, velocity and deceleration amplitudes and height; all $\mathrm{p}<.043$ ). Crucially, these interactions highlighted how, despite a similar Reach phase, development challenges the online adaptation skills between 7 and 10 years old (Figures 4a and 4b). Specifically, 7- to 8-year-old children displayed larger weight effect than older children in the unknown condition, presumably because of their higher speed when coming in contact with the object (this resulted in high amplitudes of acceleration, velocity and deceleration for this group when the weight was light; Figures $4 \mathrm{a}$ and $4 \mathrm{~b}$ ). Of interest is the time at which children managed to overcome weight effect in the known condition. Indeed, knowing the weight before grasping the object was not sufficient to abolish the weight effect in the Displace phase. The effect of the object weight lasted until the end of the Displace phase in the $7 / 8$ group, however in the $9 / 10$ group the object weight did not affect the last two parameters of the Displace phase (i.e. the deceleration peak and the maximal height). The triple interaction Knowledge *Weight *Group is well illustrated by the latest parameter of the movement (e.g. the height reached by the object during the Displace Phase, Figure $4 b$ ). Indeed, the 7/8 group, even when object weight was known and anticipated since the Reach phase, still prove to be affected by object weight till the very end of the movement (light: $207 \mathrm{~mm}$; heavy: $218 \mathrm{~mm}$; $\mathrm{SE}=4.4, \mathrm{t}=-2.5$, $\mathrm{p}=.015$; see Table 2 for mean and statistics).

\section{**Place figure 4 around here**}




\subsection{Movement time}

As expected, object weight largely affected movement time, grasping and displacing a heavy object being more time consuming than performing the same action with a light object $(5 / 6$ years old vs. $7 / 8$ years old: $\mathrm{SE}=65.7, \mathrm{t}=-2.0, \mathrm{p}=.051 ; 7 / 8$ years old vs. $9 / 10$ years old: $\mathrm{SE}=$ $65.6, \mathrm{t}=1.9, \mathrm{p}=.052 ; 5 / 6$ years old vs. $9 / 10$ years old: $\mathrm{SE}=65.1, \mathrm{t}=-0.008, \mathrm{p}=.99$; see Tables 1 and 3 for statistics and mean values).

\section{Discussion}

The present study aimed to characterize, within a single, ecological paradigm, feedforward and feedback developmental milestones in 5 to 10 years old children, using a task that could be easily transferred to children with neurodevelopmental disorders. To distinguish between feedforward and feedback strategies, we manipulated a non-visible characteristic of object, namely its weight, in a reach to displace paradigm. Feedforward strategies were observable during the Reach phase, before any haptic feedback, only when the object weight was known beforehand. Conversely, feedback processing was observable during the Displace phase, immediately after object contact. We report here two main findings: First, feedforward control is present -yet immature- before 7 years of age. Second, feedback control needs some refinement between 7 and 8 years of age before being mature at 9 years of age.

\subsection{Age-dependent strategies in anticipating object weight}

Displacing a heavy object slowed down the movement by reducing peaks amplitude, and increasing latencies for each group, protracting the displacing time. These effects due to the natural inertia of the object weight have been consistently observed in adults (Eastough \& Edwards, 2006; Johansson \& Westling, 1988; Weir et al., 1991). Indeed, when the object weight is known in advance, the anticipatory strategy consists in modulating the Reach phase to reduce the consequences of the object weight in the following Displace phase (Hermsdörfer \& Blankenfeld, 2008; Hermsdörfer et al., 2011; Nowak, Glasauer, Meyer, Mait, \& Hermsdörfer, 2002). An efficient anticipation may thus result in the total disappearance of the weight effects in the Displace phase of the movement, as shown in healthy adults and 11year-old children (Roy et al., 2013). In other words, using an efficient feedforward control allows for minimizing the need for online control. Our findings highlight two opposite strategies in the Reach phase, as a function of age. 
Children aged 5 to 6 slowed down their movement prior to contact with the heavy object, resulting in smaller peaks and increased latencies through the whole Reach phase. Five to six year-old children are thus able to use a feedforward strategy in a set of voluntary movements, as observed in motor adaptation studies (Konczak et al., 2003). This strategy is nevertheless qualitatively different from older children thus immature as observed in visual tasks (Contreras-Vidal et al., 2005; Smyth, Katamba, et al., 2004; Smyth, Peacock, et al., 2004), or in postural ones (Assaiante, Woollacott, \& Amblard, 2000; Schmitz, Martin, \& Assaiante, 1999, 2002). In keeping with previous work, our findings point to an exploratory strategy in younger children, based on sensory feedback processing (Kuhtz-Buschbeck, Stolze, BoczekFuncke, et al., 1998; Kuhtz-Buschbeck, Stolze, Jöhnk, et al., 1998; Olivier, Hay, Bard, \& Fleury, 2007; Paré \& Dugas, 1999). The anticipation we observed here may indeed reflect the transposition on the Reach phase of the weight effects felt in the Displace phase from the preceding trial. In other words, 5-6 yo children seem to "transfer" toward the Reach phase the kinematic consequences of the object weight they experienced in the Displace phase, hence accentuating the weight effect on their movement. Noteworthy, it is not the first time such a strategy is observed. Molina and collaborators (Molina, Tijus, \& Jouen, 2008) questioned the emergence of motor imagery in children. Children were asked to carry or imagine carrying a puppet that could have eaten a cake, being thus heavier. Children of 5 years of age reduced their grip force when holding the puppet they were told was heavier, while an efficient strategy would be to increase the grip force as repeatedly observed in adults (Buckingham \& Goodale, 2010; Eastough \& Edwards, 2006; Hermsdörfer \& Blankenfeld, 2008; Hermsdörfer et al., 2011; Weir et al., 1991). Our results provide additional evidence on the building of haptic feedforward control before reaching a mature strategy around 7. Despite this immature anticipation, 5-6 yo children managed to compensate the weight on the last two parameters of the movement, similarly to the 9- to 10-year-old children. The burgeoning, but still inadequate, feedforward control did not prevent the use of an efficient online control, a strategy compatible with studies observing important sensory feedback processing at this age.

Children from 7 to 10 years old displayed the strategy already observed in older children and adults. When they knew the object was heavy, children executed faster movements in the Reach phase, reducing their latencies and increasing their kinematic peaks. This strategy of speeding up the Reach phase, equally found in 10-11 yo children and healthy adults (Roy et al., 2013), is meant to increase load force and hence to prevent the lengthening of the Displace phase (Johansson \& Westling, 1988). Despite an adequate strategy, children were not able to 
avoid the protraction of the Displace phase, suggesting that their feedforward mode of control might not be fully mature at the age of 9 (Forssberg et al., 1991, 1992; Kuhtz-Buschbeck, Stolze, Jöhnk, et al., 1998; Olivier et al., 2007; Paré \& Dugas, 1999). If no major changes seemed to appear between 7 and 10 in anticipatory skills, 7-8 yo ones still raised the bottle higher when the object was heavy compared to light. Instead, 9-10 yo children succeeded in compensating the weight at the end of movement. This finding suggests that, even with similar anticipatory strategy, 7-8 years old may not be as mature as 9-10 ones regarding their online control skills.

\subsection{A weaker online control around 7 to 8 years of age}

Haptic feedback from the object was received only once the object was in hand, that is during the Displace phase. Whether the weight was known or not, the Displace phase thus witnessed the capacity of online control exhibited by children from 5 to 10. In both conditions (known and unknown weight), children aged 7 to 8 differed from the other two groups. First, when they knew the weight, and despite a correct anticipation strategy, the effect of weight lasted until the end of the movement (whereas it disappeared in the 9/10 and 5/6). Indeed, both groups raised the bottle at the same height whether it was light or heavy when they could anticipate it, while 7- to 8-year-old children were still affected by the weight on this last parameter. Second, when the weight could not be anticipated (because unknown), 7- 8 yo children exhibited difficulties when it came to control their movement amplitudes (as already reported in the literature by Hay, 1978; Hay et al., 2005; Pellizzer \& Hauert, 1996; Smyth, Katamba, et al., 2004). Younger children seemed instead better at controlling an object of unknown weight, although some methodological considerations (lighter weight, different Reach phase) could drive the interaction. This findings are in line with previous studies reporting that the behavior of 7-8 years old children differs from that of both younger and older children (Badan, Hauert, \& Mounoud, 2000; Hay, 1978; Hay et al., 2005; Pellizzer \& Hauert, 1996; Thibaut \& Toussaint, 2010). This period would thus mark a transition between the feedback-based exploratory strategy, observed in younger children and the skilled control of both feedback and feedforward strategies, found in older children. This is particularly relevant as it has been shown that online control ability can predict performance on standardized tests used in Developmental Coordination Disorder, such as the Motor Assessment Battery for Children 2 (M-ABC2; Blanchard et al., 2017). 
Taken together, these findings confirm that major changes occur in motor coordination at age 7 (Pellizzer \& Hauert, 1996) to reach a more mature, adult-like movement control pattern at around 10-11 years of age (Forssberg et al., 1991, 1992; Roy et al., 2013). During this critical transition, children develop an efficient anticipation strategy, built on the ability to invert the experienced proprioceptive feedback. This nicely fits with the idea that adjusting feedback control to the characteristics of novel motor skills is the key of acquiring them (Cluff \& Scott, 2013). This observation for voluntary movements nicely parallels that obtained in postural control, where the acquisition of anticipatory postural adjustments (APA) require the progressive transformation of feedback postural corrections into a feedforward control, which anticipates the consequences of the postural disturbance (Massion, 1992; Schmitz et al., 2002). Hence, intentional motor control seems to follow the same developmental pattern as postural control, with early emergence and slow maturation during childhood (Assaiante et al., 2000; Schmitz et al., 1999, 2002). Noteworthy, the progressive improvement in feedforward control follows the linear improvement in using proprioception for multisensorymotor integration between the age of 5 and 12 (Visser \& Geuze, 2000). As children are more and more able to integrate proprioceptive feedback, they may become capable of twisting them into a strategic feedforward control (King, Pangelinan, Kagerer, \& Clark, 2010). Conversely, as visual acuity matures earlier (Leat, Yadav, \& Irving, 2009), children might be able to integrate visual feedback earlier (Hay, 1978; Smyth, Katamba, et al., 2004; Zoia et al., 2006).

To summarize, from 5 to 10 years of age, children develop the capability of efficiently anticipating object properties in their motor programs. Two steps are noticeable before an adult-like strategy is set around 9 to 10 years. First, anticipatory control might evolve from feedback processing, as suggested by the immature anticipatory behavior exhibited by 5 to 6 years old children. Second, by 7 to 8 years, a transition operates and as the feedforward control becomes efficient, the online control appears temporarily less reliable.

\section{Acknowledgements}

We thank the children and families for their participation. This research has received the support from the ANR Samenta (ASD-BARN 01502) and the ANR Developmental Tool Mastery. MM was supported by a grant from the French Ministry of Higher Education and Research.

\section{Conflict of interest statement}


The authors declare no conflict of interest.

\section{References}

Ansuini, C., Cavallo, A., Campus, C., Quarona, D., Koul, A., \& Becchio, C. (2016). Are We Real When We Fake? Attunement to Object Weight in Natural and Pantomimed Grasping Movements. Frontiers in Human Neuroscience, 10. https://doi.org/10.3389/fnhum.2016.00471

Ansuini, C., Cavallo, A., Koul, A., Jacono, M., Yang, Y., \& Becchio, C. (2015). Predicting object size from hand kinematics: a temporal perspective. PloS One, 10(3), e0120432. https://doi.org/10.1371/journal.pone.0120432

Ansuini, C., Giosa, L., Turella, L., Altoè, G., \& Castiello, U. (2008). An object for an action, the same object for other actions: effects on hand shaping. Experimental Brain Research, 185(1), 111-119. https://doi.org/10.1007/s00221-007-1136-4

Ansuini, C., Podda, J., Battaglia, F. M., Veneselli, E., \& Becchio, C. (2018). One hand, two hands, two people: Prospective sensorimotor control in children with autism. Developmental Cognitive Neuroscience, 29, 86-96. https://doi.org/10.1016/j.dcn.2017.02.009

Assaiante, C., Woollacott, M., \& Amblard, B. (2000). Development of Postural Adjustment During Gait Initiation: Kinematic and EMG Analysis. Journal of Motor Behavior, 32(3), 211-226. https://doi.org/10.1080/00222890009601373

Babinsky, E., Braddick, O., \& Atkinson, J. (2012). The effect of removing visual information on reach control in young children. Experimental Brain Research, 222(3), 291-302. https://doi.org/10.1007/s00221-012-3216-3

Badan, M., Hauert, C. A., \& Mounoud, P. (2000). Sequential pointing in children and adults. Journal of Experimental Child Psychology, 75(1), 43-69. https://doi.org/10.1006/jecp.1999.2522

Basso, D., \& Finos, L. (2012). Exact Multivariate Permutation Tests for Fixed Effects in Mixed-Models. Communications in Statistics - Theory and Methods, 41(16-17), 2991-3001. https://doi.org/10.1080/03610926.2011.627103

Becchio, C., Zanatto, D., Straulino, E., Cavallo, A., Sartori, G., \& Castiello, U. (2014). The kinematic signature of voluntary actions. Neuropsychologia, 64, 169-175. https://doi.org/10.1016/j.neuropsychologia.2014.09.033

Berthier, N. E., \& Carrico, R. L. (2010). Visual information and object size in infant reaching. Infant Behavior \& Development, 33(4), 555-566. https://doi.org/10.1016/j.infbeh.2010.07.007

Blanchard, C. C. V., McGlashan, H. L., French, B., Sperring, R. J., Petrocochino, B., \& Holmes, N. P. (2017). Online Control of Prehension Predicts Performance on a Standardized Motor Assessment Test in 8- to 12-Year-Old Children. Frontiers in Psychology, 8, 374. https://doi.org/10.3389/fpsyg.2017.00374

Boisgontier, M. P., \& Cheval, B. (2016). The anova to mixed model transition. Neuroscience \& Biobehavioral Reviews, 68, 1004-1005. https://doi.org/10.1016/j.neubiorev.2016.05.034

Brenner, E., \& Smeets, J. B. (1996). Size illusion influences how we lift but not how we grasp an object. Experimental Brain Research, 111(3), 473-476.

Brenner, E., \& Smeets, J. B. (1997). Fast Responses of the Human Hand to Changes in Target Position. Journal of Motor Behavior, 29(4), 297-310. https://doi.org/10.1080/00222899709600017

Brouwer, A.-M., Georgiou, I., Glover, S., \& Castiello, U. (2006). Adjusting reach to lift movements to sudden visible changes in target's weight. Experimental Brain Research, 173(4), 629-636. https://doi.org/10.1007/s00221-006-0406-x

Buckingham, G., \& Goodale, M. A. (2010). The influence of competing perceptual and motor priors in the context of the size-weight illusion. Experimental Brain Research, 205(2), 283-288. https://doi.org/10.1007/s00221-010-2353-9 
Buckingham, G., Ranger, N. S., \& Goodale, M. A. (2011). The role of vision in detecting and correcting fingertip force errors during object lifting. Journal of Vision, 11(1), 4-4. https://doi.org/10.1167/11.1.4

Cashaback, J. G. A., McGregor, H. R., Pun, H. C. H., Buckingham, G., \& Gribble, P. L. (2017). Does the sensorimotor system minimize prediction error or select the most likely prediction during object lifting? Journal of Neurophysiology, 117(1), 260-274. https://doi.org/10.1152/jn.00609.2016

Castiello, U., Bennett, K. M. B., \& Stelmach, G. E. (1993). Reach to grasp: the natural response to perturbation of object size. Experimental Brain Research, 94(1), 163-178.

https://doi.org/10.1007/BF00230479

Chouinard, P. A. (2005). Role of the Primary Motor and Dorsal Premotor Cortices in the Anticipation of Forces during Object Lifting. Journal of Neuroscience, 25(9), 2277-2284. https://doi.org/10.1523/JNEUROSCI.4649-04.2005

Cluff, T., \& Scott, S. H. (2013). Rapid Feedback Responses Correlate with Reach Adaptation and Properties of Novel Upper Limb Loads. The Journal of Neuroscience, 33(40), 15903-15914. https://doi.org/10.1523/JNEUROSCI.0263-13.2013

Contreras-Vidal, J. L., Bo, J., Boudreau, J. P., \& Clark, J. E. (2005). Development of visuomotor representations for hand movement in young children. Experimental Brain Research, 162(2), 155164. https://doi.org/10.1007/s00221-004-2123-7

Desmurget, M., \& Grafton, S. (2000). Forward modeling allows feedback control for fast reaching movements. Trends in Cognitive Sciences, 4(11), 423-431.

Desmurget, M., \& Grafton, S. (2003). Feedback or Feedforward Control: End of. Taking action: Cognitive neuroscience perspectives on intentional acts, 289.

Desmurget, M., Prablanc, C., Arzi, M., Rossetti, Y., Paulignan, Y., \& Urquizar, C. (1996). Integrated control of hand transport and orientation during prehension movements. Experimental Brain Research, 110(2), 265-278. https://doi.org/10.1007/BF00228557

Eastough, D., \& Edwards, M. G. (2006). Movement kinematics in prehension are affected by grasping objects of different mass. Experimental Brain Research, 176(1), 193-198. https://doi.org/10.1007/s00221-006-0749-3

Ernst, M. O., \& Banks, M. S. (2002). Humans integrate visual and haptic information in a statistically optimal fashion. Nature, 415(6870), 429-433. https://doi.org/10.1038/415429a

Farnè, A., Roy, A. C., Paulignan, Y., Rode, G., Rossetti, Y., Boisson, D., \& Jeannerod, M. (2003). Visuomotor control of the ipsilateral hand: evidence from right brain-damaged patients. Neuropsychologia, 41(6), 739-757.

Flanagan, J. R., King, S., Wolpert, D. M., \& Johansson, R. S. (2001). Sensorimotor prediction and memory in object manipulation. Canadian Journal of Experimental Psychology $=$ Revue Canadienne De Psychologie Expérimentale, 55(2), 87-95.

Flash, T., \& Henis, E. (1991). Arm Trajectory Modifications During Reaching Towards Visual Targets. Journal of Cognitive Neuroscience, 3(3), 220-230. https://doi.org/10.1162/jocn.1991.3.3.220

Forssberg, H., Eliasson, A. C., Kinoshita, H., Johansson, R. S., \& Westling, G. (1991). Development of human precision grip. I: Basic coordination of force. Experimental Brain Research, 85(2), 451-457.

Forssberg, H., Kinoshita, H., Eliasson, A. C., Johansson, R. S., Westling, G., \& Gordon, A. M. (1992). Development of human precision grip. II. Anticipatory control of isometric forces targeted for object's weight. Experimental Brain Research, 90(2), 393-398.

Gachoud, J. P., Mounoud, P., Hauert, C. A., \& Viviani, P. (1983). Motor strategies in lifting movements: a comparison of adult and child performance. Journal of Motor Behavior, 15(3), 202216.

Gentilucci, M. (2002). Object motor representation and reaching-grasping control. Neuropsychologia, 40(8), 1139-1153. 
Gordon, A. M., Forssberg, H., Johansson, R. S., \& Westling, G. (1991a). The integration of haptically acquired size information in the programming of precision grip. Experimental Brain Research, 83(3), 483-488.

Gordon, A. M., Forssberg, H., Johansson, R. S., \& Westling, G. (1991b). Visual size cues in the programming of manipulative forces during precision grip. Experimental Brain Research, 83(3), 477-482.

Gordon, A. M., Westling, G., Cole, K. J., \& Johansson, R. S. (1993). Memory representations underlying motor commands used during manipulation of common and novel objects. Journal of Neurophysiology, 69(6), 1789-1796.

Gori, M., Del Viva, M., Sandini, G., \& Burr, D. C. (2008). Young children do not integrate visual and haptic form information. Current Biology: CB, 18(9), 694-698. https://doi.org/10.1016/j.cub.2008.04.036

Gréa, H., Desmurget, M., \& Prablanc, C. (2000). Postural invariance in three-dimensional reaching and grasping movements. Experimental Brain Research, 134(2), 155-162.

Hay, L. (1978). Accuracy of children on an open-loop pointing task. Perceptual and Motor Skills, 47(3 Pt 2), 1079-1082. https://doi.org/10.2466/pms.1978.47.3f.1079

Hay, L., Bard, C., Ferrel, C., Olivier, I., \& Fleury, M. (2005). Role of proprioceptive information in movement programming and control in 5 to 11 -year old children. Human Movement Science, 24(2), 139-154. https://doi.org/10.1016/j.humov.2005.05.002

Hay, L., Fleury, M., Bard, C., \& Teasdale, N. (1994). Resolving power of the perceptual- and sensorimotor systems in 6- to 10-year-old children. Journal of Motor Behavior, 26(1), 36-42. https://doi.org/10.1080/00222895.1994.9941659

Hermsdörfer, J., \& Blankenfeld, H. (2008). Grip force control of predictable external loads. Experimental Brain Research, 185(4), 719-728. https://doi.org/10.1007/s00221-007-1195-6

Hermsdörfer, J., Li, Y., Randerath, J., Goldenberg, G., \& Eidenmüller, S. (2011). Anticipatory scaling of grip forces when lifting objects of everyday life. Experimental Brain Research, 212(1), 19-31. https://doi.org/10.1007/s00221-011-2695-y

Hyde, C. E., \& Wilson, P. H. (2011a). Dissecting online control in Developmental Coordination Disorder: A kinematic analysis of double-step reaching. Brain and Cognition, 75(3), 232-241. https://doi.org/10.1016/j.bandc.2010.12.004

Hyde, C. E., \& Wilson, P. H. (2011b). Online motor control in children with developmental coordination disorder: chronometric analysis of double-step reaching performance. Child: Care, Health and Development, 37(1), 111-122. https://doi.org/10.1111/j.1365-2214.2010.01131.x

Jeannerod, M. (1984). The timing of natural prehension movements. Journal of Motor Behavior, 16(3), 235-254.

Johansson, R. S., \& Westling, G. (1984). Roles of glabrous skin receptors and sensorimotor memory in automatic control of precision grip when lifting rougher or more slippery objects. Experimental Brain Research, 56(3), 550-564.

Johansson, R. S., \& Westling, G. (1988). Coordinated isometric muscle commands adequately and erroneously programmed for the weight during lifting task with precision grip. Experimental Brain Research, 71(1), 59-71.

King, B. R., Pangelinan, M. M., Kagerer, F. A., \& Clark, J. E. (2010). Improvements in proprioceptive functioning influence multisensory-motor integration in 7- to 13-year-old children. Neuroscience Letters, 483(1), 36-40. https://doi.org/10.1016/j.neulet.2010.07.056

Konczak, J., Jansen-Osmann, P., \& Kalveram, K.-T. (2003). Development of force adaptation during childhood. Journal of Motor Behavior, 35(1), 41-52. https://doi.org/10.1080/00222890309602120

Kuhtz-Buschbeck, J. P., Stolze, H., Boczek-Funcke, A., Jöhnk, K., Heinrichs, H., \& Illert, M. (1998). Kinematic analysis of prehension movements in children. Behavioural brain research, 93(1), 131141. 
Kuhtz-Buschbeck, J. P., Stolze, H., Jöhnk, K., Boczek-Funcke, A., \& Illert, M. (1998). Development of prehension movements in children: a kinematic study. Experimental Brain Research, 122(4), 424432.

Leat, S. J., Yadav, N. K., \& Irving, E. L. (2009). Development of Visual Acuity and Contrast Sensitivity in Children. Journal of Optometry, 2(1), 19-26. https://doi.org/10.3921/joptom.2009.19

Massion, J. (1992). Movement, posture and equilibrium: interaction and coordination. Progress in Neurobiology, 38(1), 35-56.

Molina, M., Tijus, C., \& Jouen, F. (2008). The emergence of motor imagery in children. Journal of Experimental Child Psychology, 99(3), 196-209. https://doi.org/10.1016/j.jecp.2007.10.001

Nardini, M., Begus, K., \& Mareschal, D. (2013). Multisensory uncertainty reduction for hand localization in children and adults. Journal of Experimental Psychology. Human Perception and Performance, 39(3), 773-787. https://doi.org/10.1037/a0030719

Nardini, M., Jones, P., Bedford, R., \& Braddick, O. (2008). Development of Cue Integration in Human Navigation. Current Biology, 18(9), 689-693. https://doi.org/10.1016/j.cub.2008.04.021

Nowak, D. A., Glasauer, S., Meyer, L., Mait, N., \& Hermsdörfer, J. (2002). The role of cutaneous feedback for anticipatory grip force adjustments during object movements and externally imposed variation of the direction of gravity. Somatosensory \& Motor Research, 19(1), 49-60.

Olivier, I., Hay, L., Bard, C., \& Fleury, M. (2007). Age-related differences in the reaching and grasping coordination in children: unimanual and bimanual tasks. Experimental Brain Research, 179(1), 1727. https://doi.org/10.1007/s00221-006-0762-6

Paré, M., \& Dugas, C. (1999). Developmental changes in prehension during childhood. Experimental brain research, 125(3), 239-247.

Paulignan, Y., Mackenzie, C., Marteniuk, R., \& Jeannerod, M. (1991). Selective perturbation of visual input during prehension movements. 1. The effects of changing object position. Experimental Brain Research, 83(3), 502-512.

Pellizzer, G., \& Hauert, C.-A. (1996). Visuo-manual aiming movements in 6-to 10-year-old children: evidence for an asymmetric and asynchronous development of information processes. Brain and cognition, 30(2), 175-193.

Pesarin, F. (2001). Multivariate Permutation Tests: With Applications in Biostatistics. Wiley.

Plumb, M. S., Wilson, A. D., Mulroue, A., Brockman, A., Williams, J. H. G., \& Mon-Williams, M. A. (2008). Online corrections in children with and without DCD. Human Movement Science, 27(5), 695-704. https://doi.org/10.1016/j.humov.2007.11.004

R Core Team. (2018). R: A language and environment for statistical computing. R Foundation for Statistical Computing, Vienna, Austria. URL https://www.R-project.org/.

Roy, A. C., Curie, A., Nazir, T., Paulignan, Y., des Portes, V., Fourneret, P., \& Deprez, V. (2013). Syntax at hand: common syntactic structures for actions and language. PloS One, 8(8), e72677. https://doi.org/10.1371/journal.pone.0072677

Roy, A. C., Paulignan, Y., Meunier, M., \& Boussaoud, D. (2006). Prehension movements in the macaque monkey: effects of perturbation of object size and location. Experimental Brain Research, 169(2), 182-193. https://doi.org/10.1007/s00221-005-0133-8

Salimi, I., Hollender, I., Frazier, W., \& Gordon, A. M. (2000). Specificity of Internal Representations Underlying Grasping. Journal of Neurophysiology, 84(5), 2390-2397.

Sarlegna, F. R. (2006). Impairment of online control of reaching movements with aging: A doublestep study. Neuroscience Letters, 403(3), 309-314. https://doi.org/10.1016/j.neulet.2006.05.003

Sarlegna, F. R., Blouin, J., Bresciani, J.-P., Bourdin, C., Vercher, J.-L., \& Gauthier, G. M. (2003). Target and hand position information in the online control of goal-directed arm movements.

Experimental Brain Research, 151(4), 524-535. https://doi.org/10.1007/s00221-003-1504-7

Sarlegna, F. R., \& Mutha, P. K. (2015). The influence of visual target information on the online control of movements. Vision Research, 110(Pt B), 144-154. https://doi.org/10.1016/j.visres.2014.07.001 
Saunders, J. A., \& Knill, D. C. (2004). Visual feedback control of hand movements. The Journal of Neuroscience: The Official Journal of the Society for Neuroscience, 24(13), 3223-3234. https://doi.org/10.1523/JNEUROSCI.4319-03.2004

Schmitz, C., Jenmalm, P., Ehrsson, H. H., \& Forssberg, H. (2005). Brain activity during predictable and unpredictable weight changes when lifting objects. Journal of Neurophysiology, 93(3), 1498-1509. https://doi.org/10.1152/jn.00230.2004

Schmitz, C., Martin, N., \& Assaiante, C. (1999). Development of anticipatory postural adjustments in a bimanual load-lifting task in children. Experimental Brain Research, 126(2), 200-204.

Schmitz, C., Martin, N., \& Assaiante, C. (2002). Building anticipatory postural adjustment during childhood: a kinematic and electromyographic analysis of unloading in children from 4 to 8 years of age. Experimental brain research. Experimentelle Hirnforschung. Expérimentation cérébrale, 142(3), 354-364. https://doi.org/10.1007/s00221-001-0910-y

Schneiberg, S., Sveistrup, H., McFadyen, B., McKinley, P., \& Levin, M. F. (2002). The development of coordination for reach-to-grasp movements in children. Experimental Brain Research, 146(2), 142 -154. https://doi.org/10.1007/s00221-002-1156-z

Smeets, J. B., \& Brenner, E. (1999). A new view on grasping. Motor Control, 3(3), 237-271.

Smyth, M. M., Anderson, H. I., \& Churchill, A. C. (2001). Visual information and the control of reaching in children: a comparison between children with and without developmental coordination disorder. Journal of Motor Behavior, 33(3), 306-320. https://doi.org/10.1080/00222890109601916

Smyth, M. M., Katamba, J., \& Peacock, K. A. (2004). Development of prehension between 5 and 10 years of age: distance scaling, grip aperture, and sight of the hand. Journal of Motor Behavior, 36(1), 91-103. https://doi.org/10.3200/JMBR.36.1.91-103

Smyth, M. M., Peacock, K. A., \& Katamba, J. (2004). The role of sight of the hand in the development of prehension in childhood. The Quarterly Journal of Experimental Psychology. A, Human Experimental Psychology, 57(2), 269-296. https://doi.org/10.1080/02724980343000215

Sober, S. J., \& Sabes, P. N. (2003). Multisensory integration during motor planning. The Journal of Neuroscience: The Official Journal of the Society for Neuroscience, 23(18), 6982-6992.

Sumner, E., Leonard, H. C., \& Hill, E. L. (2016). Overlapping Phenotypes in Autism Spectrum Disorder and Developmental Coordination Disorder: A Cross-Syndrome Comparison of Motor and Social Skills. Journal of Autism and Developmental Disorders, 46(8), 2609-2620. https://doi.org/10.1007/s10803-016-2794-5

Thévenet, M., Paulignan, Y., \& Prablanc, C. (2001). OPTODISP Program, License INSERM-CNRS-UCBL. Thibaut, J.-P., \& Toussaint, L. (2010). Developing motor planning over ages. Journal of Experimental Child Psychology, 105(1-2), 116-129. https://doi.org/10.1016/j.jecp.2009.10.003

Veerman, M. M., Brenner, E., \& Smeets, J. B. J. (2008). The latency for correcting a movement depends on the visual attribute that defines the target. Experimental Brain Research, 187(2), 219228. https://doi.org/10.1007/s00221-008-1296-x

Visser, J., \& Geuze, R. H. (2000). Kinaesthetic acuity in adolescent boys: a longitudinal study. Developmental Medicine and Child Neurology, 42(2), 93-96.

Voudouris, D., Smeets, J. B. J., \& Brenner, E. (2013). Ultra-fast selection of grasping points. Journal of Neurophysiology, 110(7), 1484-1489. https://doi.org/10.1152/jn.00066.2013

Weir, P. L., MacKenzie, C. L., Marteniuk, R. G., Cargoe, S. L., \& Frazer, M. B. (1991). The effects of object weight on the kinematics of prehension. Journal of Motor Behavior, 23(3), 192-204. https://doi.org/10.1080/00222895.1991.10118362

Westling, G., \& Johansson, R. S. (1984). Factors influencing the force control during precision grip. Experimental Brain Research, 53(2), 277-284.

Wilson, P. H., \& Hyde, C. E. (2013). The development of rapid online control in children aged 612 years: Reaching performance. Human Movement Science.

https://doi.org/10.1016/j.humov.2013.02.008 
Zhang, Y., Brenner, E., Duysens, J., Verschueren, S., \& Smeets, J. B. J. (2018). Postural responses to target jumps and background motion in a fast pointing task. Experimental Brain Research, 236(6), 1573-1581. https://doi.org/10.1007/s00221-018-5222-6

Zoia, S., Pezzetta, E., Blason, L., Scabar, A., Carrozzi, M., Bulgheroni, M., \& Castiello, U. (2006). A Comparison of the Reach-To-Grasp Movement Between Children and Adults: A Kinematic Study. Developmental Neuropsychology, 30(2), 719-738. https://doi.org/10.1207/s15326942dn3002_4 
Figures

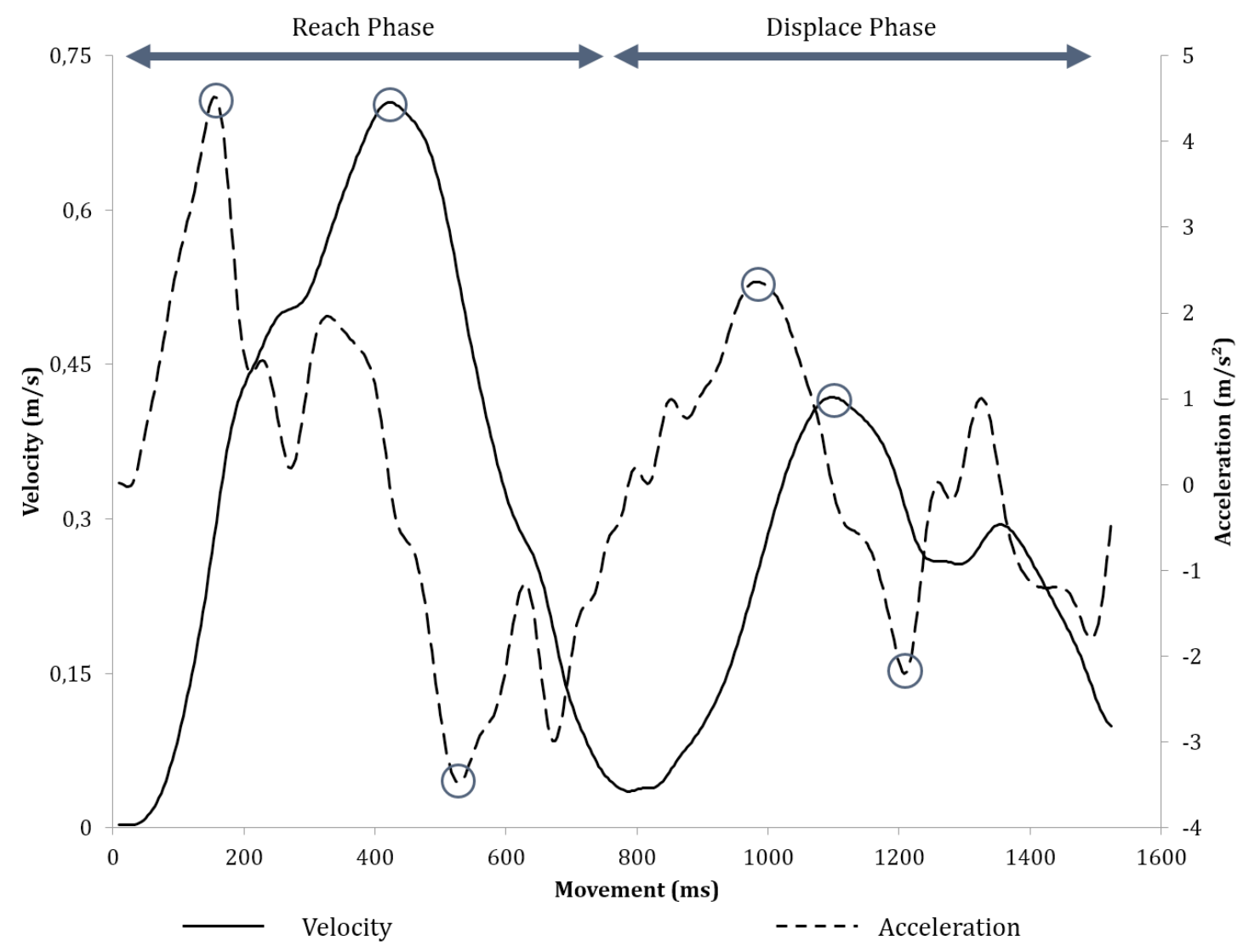

Fig. 1 Kinematic data of a single trial from a subject, separated in a Reach and a

Displace phase. Circled peaks are extracted for the analyses, either in amplitudes $(\mathrm{mm} / \mathrm{s}$ or $\mathrm{mm} / \mathrm{s}^{2}$ ) or in latencies $(\mathrm{ms})$. 


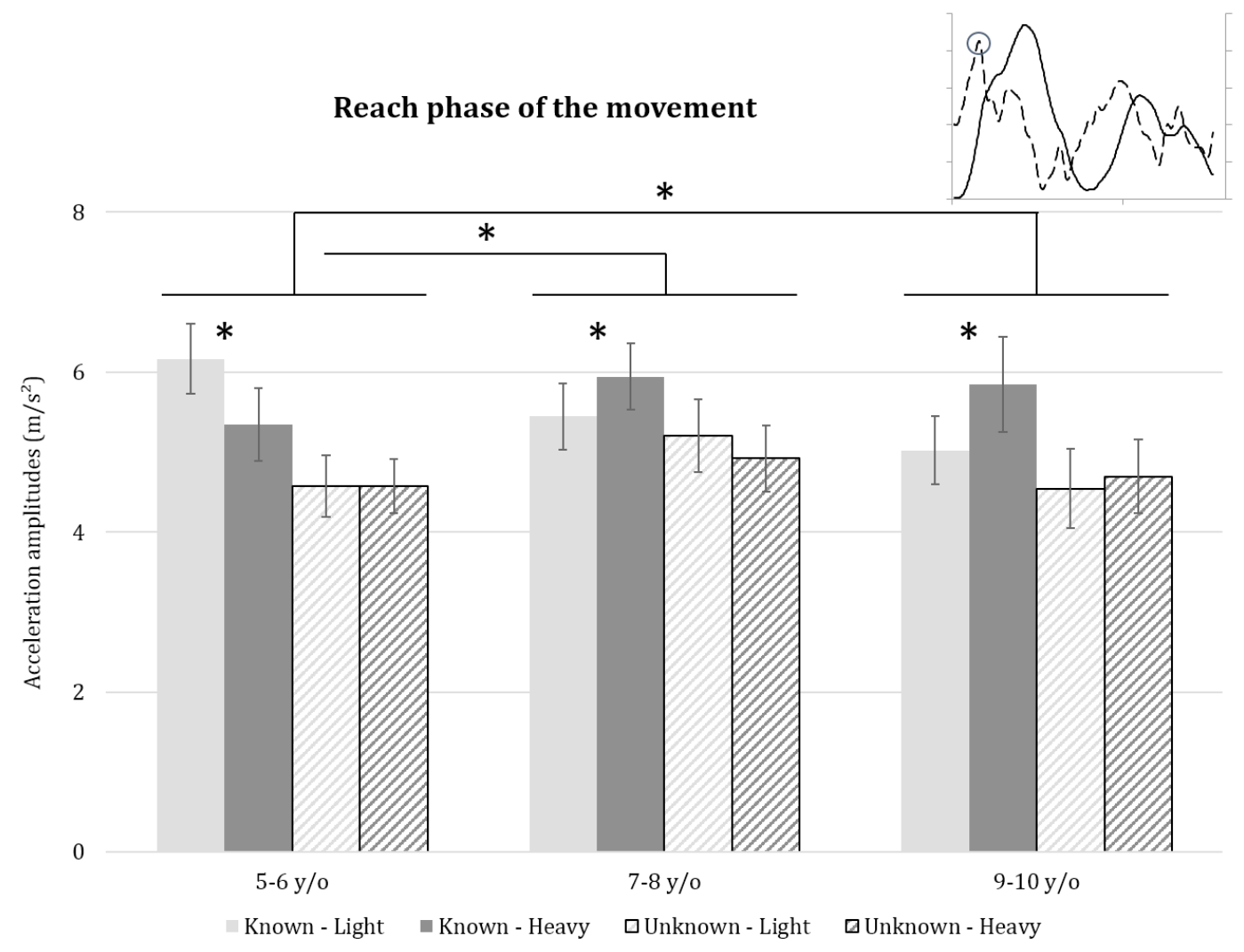

Fig. 2 Triple interaction Knowledge *Weight *Group for the acceleration peak in the Reach phase of the movement. The modulation according to the weight is opposite between the 5/6 children and the older groups when it is known. Conversely, when given no information about the weight, none of the group modulated their movement as a function of the weight. Bar graphs illustrate mean values for each group \pm sem. * indicates significance. 

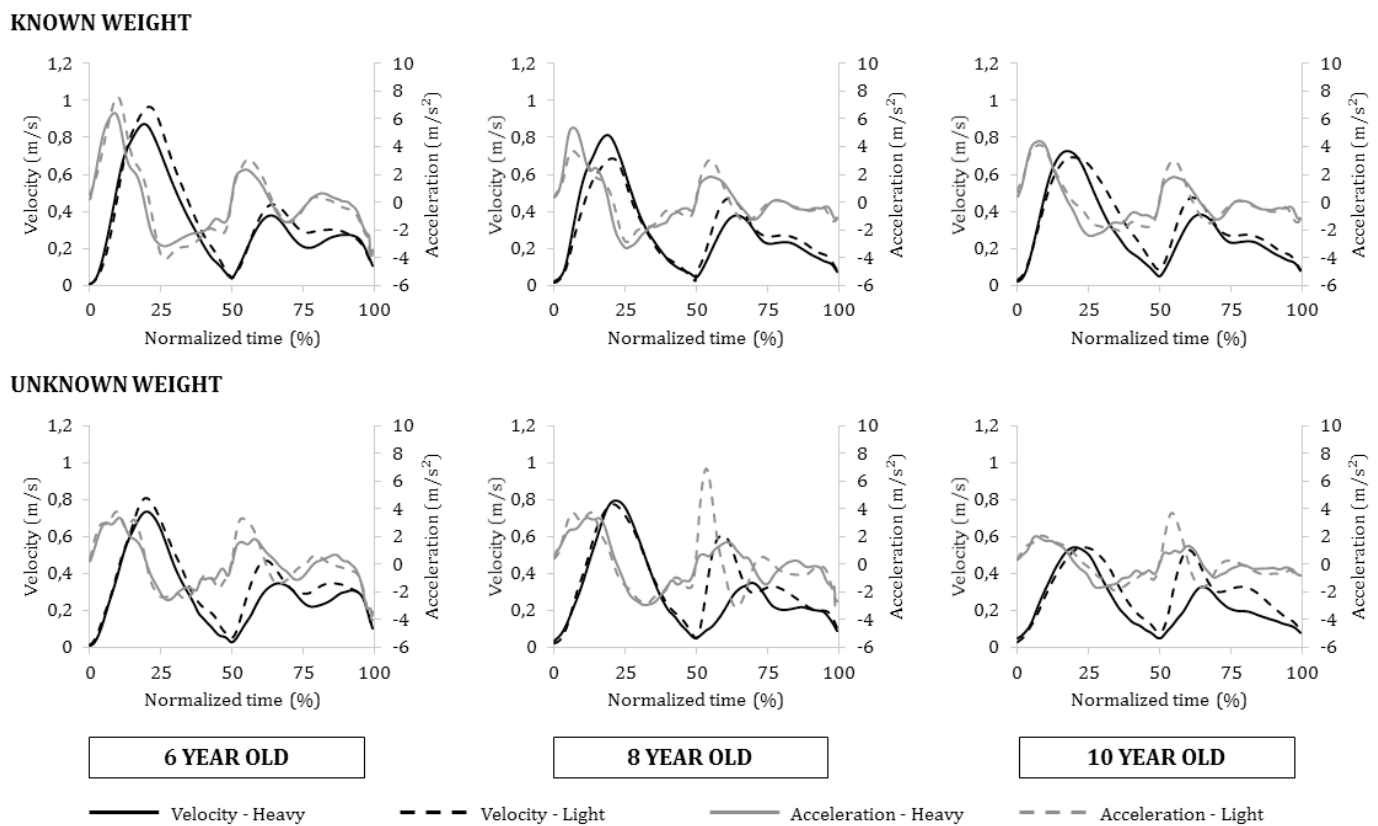

6 YEAR OLD

- Acceleration - Heavy

10 YEAR OLD

Fig. 3. Kinematic profiles of representative subjects of each group, for all the conditions. Velocity is in black, while acceleration is in grey. The dashed lines represent the light object and the solid ones the heavy object. Changes of strategy with age are clearly visible (such as increase peaks for the light object in 6-year-old children, but the opposite for the older children). 


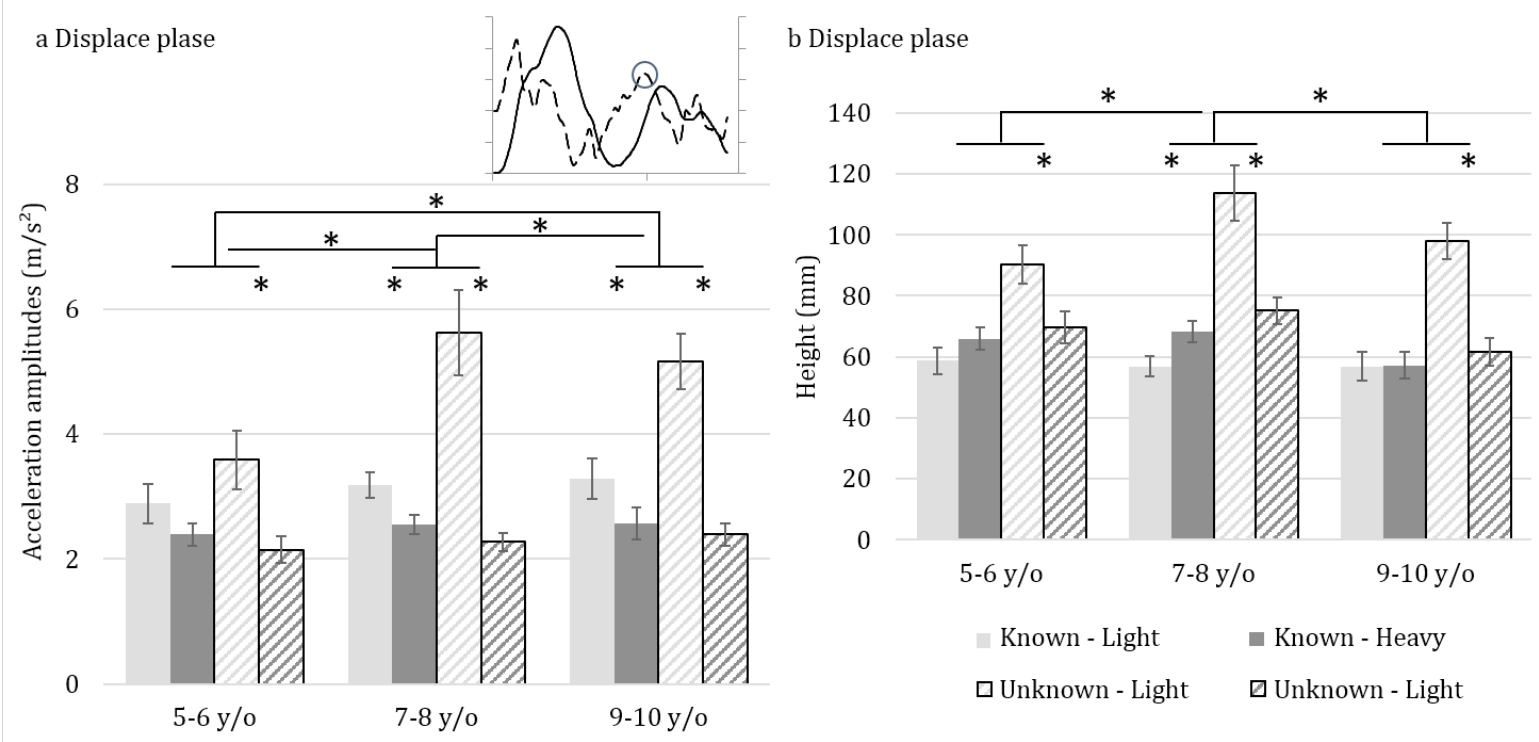

Fig. 4 (a) Triple interactions weight *knowledge *group for the maximal acceleration peaks in the Displace phase of the movement. When they could not anticipate the weight (dashed bars), the 7/8 group of children got more carried away than the 9/10 group, even if they used a similar adult-like strategy in the Reach phase. (b) Triple interactions weight *knowledge *group for the maximal height of the bottle in the Displace phase of the movement. When previously known (solid bars), only the $9 / 10$ group fully overcame the weight effect, while the 7/8 did not, even if they used a similar adult-like strategy in the Reach phase. Bar graphs illustrate mean values for each group \pm sem. * indicates significance. 
Table 1. Triple interaction group $x$ weight $x$ knowledge of all the parameters from the Reach phase, the Displace phase and the movement time. P-values are in bold when significant. MGA = Maximum Grip Aperture.

\begin{tabular}{|c|c|c|c|c|c|c|c|c|c|}
\hline \multirow[b]{3}{*}{ Reach Phase } & \multicolumn{3}{|c|}{ Group * Weight * } & \multicolumn{3}{|c|}{ Group $*$ Weight $*$} & \multicolumn{3}{|c|}{ Group * Weight * } \\
\hline & \multicolumn{3}{|c|}{$5 / 6$ vs. $7 / 8$} & \multicolumn{3}{|c|}{$5 / 6$ vs. $9 / 10$} & \multicolumn{3}{|c|}{$7 / 8$ vs. $9 / 10$} \\
\hline & SE & $\mathrm{t}$ & $p$ & SE & $\mathrm{t}$ & $p$ & SE & $\mathrm{t}$ & $p$ \\
\hline Acceleration Latency & 22.4 & 0.89 & .373 & 21.8 & 0.85 & .396 & 21.5 & -0.07 & .945 \\
\hline Acceleration Peak & 462 & 2.96 & .003 & 449 & 3.02 & .003 & 444 & -0.03 & .980 \\
\hline Velocity Latency & 21.8 & -1.05 & .295 & 21.6 & -0.71 & .476 & 21.7 & 0.34 & .733 \\
\hline Velocity Peak & 29.1 & 2.21 & .027 & 28.9 & 3.11 & .002 & 29.1 & 0.87 & .384 \\
\hline Deceleration Latency & 30.4 & -2.37 & .018 & 30.2 & -3.04 & .002 & 30.4 & -0.65 & .519 \\
\hline Deceleration Peak & 344 & -3.01 & .003 & 341 & -3.35 & $<.001$ & 343 & -0.32 & .747 \\
\hline MGA Latency & 37.2 & -1.20 & .232 & 36.7 & -1.40 & .161 & 37.3 & -0.19 & .849 \\
\hline MGA & 2.23 & 0.58 & .563 & 2.21 & 2.62 & .009 & 2.24 & 2.01 & .045 \\
\hline Displace Phase & $\mathrm{SE}$ & $\mathrm{t}$ & $p$ & $\mathrm{SE}$ & $\mathrm{t}$ & $p$ & SE & $\mathrm{t}$ & $p$ \\
\hline Acceleration Latency & 44.7 & -2.05 & .040 & 44.3 & -1.92 & .056 & 44.6 & 0.15 & .878 \\
\hline Acceleration Peak & 301 & 5.94 & $<.001$ & 299 & 3.66 & $<.001$ & 301 & -2.32 & .020 \\
\hline Velocity Latency & 45.8 & -1.09 & .274 & 45.4 & -0.92 & .360 & 45.7 & 0.19 & .853 \\
\hline Velocity Peak & 22.7 & 5.60 & $<.001$ & 22.6 & 2.27 & .024 & 22.7 & -3.36 & $<.001$ \\
\hline Deceleration Latency & 47.9 & -0.91 & .363 & 47.5 & -1.41 & .160 & 47.9 & -0.49 & .627 \\
\hline Deceleration Peak & 265 & -4.96 & $<.001$ & 263 & -2.61 & .009 & 265 & 2.38 & .018 \\
\hline Height & 6.33 & 3.36 & $<.001$ & 6.27 & 1.36 & .174 & 6.29 & -2.03 & .043 \\
\hline Movement time & SE & $\mathrm{t}$ & $\mathrm{p}$ & SE & $\mathrm{t}$ & $\mathrm{p}$ & $\mathrm{SE}$ & $t$ & $\mathrm{p}$ \\
\hline Movement time & 65.7 & -1.953 & .051 & 65.1 & -0.01 & .994 & 65.6 & 1.95 & .052 \\
\hline
\end{tabular}


Table 2. Mean and statistics regarding the weight effect in the Reach phase for a known or unknown weight. P-values are in bold when significant. All the latencies are expressed in $\mathrm{ms}$, the acceleration and deceleration peaks in $\mathrm{mm} / \mathrm{s}^{2}$, the velocity in $\mathrm{mm} / \mathrm{s}$ and the MGA (Maximum Grip Aperture) in mm.

\begin{tabular}{|c|c|c|c|c|c|c|c|c|c|c|c|c|c|c|c|}
\hline KNOWN & \multicolumn{5}{|c|}{ Weight } & \multicolumn{5}{|c|}{ Weight } & \multicolumn{5}{|c|}{ Weight } \\
\hline & \multicolumn{5}{|c|}{$5 / 6$} & \multicolumn{5}{|c|}{$7 / 8$} & \multicolumn{5}{|c|}{$9 / 10$} \\
\hline Reach Phase & Light & Heavy & SE & $\mathrm{t}$ & $p$ & Light & Heavy & $\mathrm{SE}$ & $\mathrm{t}$ & $p$ & Light & Heavy & $\mathrm{SE}$ & $\mathrm{t}$ & $p$ \\
\hline Acceleration Latency & 184 & 182 & 11.3 & 0.26 & .797 & 191 & 181 & 10.7 & 0.73 & .467 & 202 & 201 & 10.6 & 0.06 & .949 \\
\hline Acceleration Peak & 6165 & 5344 & 235 & 3.52 & $<.001$ & 5445 & 5945 & 221 & -2.17 & .031 & 5024 & 5849 & 220 & -3.52 & $<.001$ \\
\hline Velocity Latency & 350 & 377 & 11.6 & -2.33 & .023 & 369 & 341 & 11.1 & 2.34 & .022 & 368 & 366 & 11.7 & 0.06 & .955 \\
\hline Velocity Peak & 758 & 720 & 16.0 & 2.36 & .021 & 792 & 826 & 16.1 & -2.14 & .035 & 759 & 825 & 16.1 & -4.13 & $<.001$ \\
\hline Deceleration Latency & 461 & 501 & 15.9 & -2.45 & .015 & 485 & 459 & 16.0 & 1.77 & .078 & 525 & 500 & 16.0 & 1.55 & .122 \\
\hline Deceleration Peak & -4051 & -3555 & 173 & -2.85 & .005 & -4231 & -4470 & 174 & 1.43 & .157 & -3721 & -4342 & 174 & 3.44 & $<.001$ \\
\hline MGA Latency & 583 & 644 & 19.4 & -1.34 & .183 & 540 & 504 & 19.3 & 2.51 & .013 & 664 & 612 & 18.5 & 1.47 & .142 \\
\hline MGA & 87.2 & 86.2 & 1.41 & 0.99 & .329 & 88.2 & 86.1 & 1.40 & 1.98 & .054 & 79.3 & 80.3 & 1.33 & -1.19 & .242 \\
\hline \multirow[t]{2}{*}{ UNKNOWN } & \multicolumn{5}{|c|}{ Weight } & \multicolumn{5}{|c|}{ Weight } & \multicolumn{5}{|c|}{ Weight } \\
\hline & \multicolumn{5}{|c|}{$5 / 6$} & \multicolumn{5}{|c|}{$7 / 8$} & \multicolumn{5}{|c|}{$9 / 10$} \\
\hline Reach Phase & Light & Heavy & $\mathrm{SE}$ & $\mathrm{t}$ & $p$ & Light & Heavy & $\mathrm{SE}$ & $\mathrm{t}$ & $p$ & Light & Heavy & $\mathrm{SE}$ & $\mathrm{t}$ & $p$ \\
\hline Acceleration Latency & 240 & 253 & 11.5 & -1.69 & .092 & 238 & 234 & 11.7 & 0.45 & .651 & 233 & 236 & 10.5 & -0.31 & .757 \\
\hline Acceleration Peak & 4577 & 4576 & 237 & 0.40 & .689 & 5204 & 4922 & 240 & 0.69 & .490 & 4544 & 4695 & 215 & -0.68 & .497 \\
\hline Velocity Latency & 433 & 440 & 11.7 & -0.68 & .499 & 419 & 396 & 11.9 & 2.00 & .049 & 422 & 417 & 11.6 & 0.38 & .706 \\
\hline Velocity Peak & 737 & 724 & 16.1 & 0.82 & .415 & 839 & 833 & 16.3 & 0.33 & .746 & 781 & 782 & 15.9 & -0.08 & .938 \\
\hline Deceleration Latency & 569 & 553 & 16.0 & 0.94 & .350 & 554 & 543 & 16.2 & 0.61 & .542 & 546 & 559 & 15.8 & -0.84 & .401 \\
\hline Deceleration Peak & -3544 & -3644 & 174 & 0.54 & .589 & -4326 & -4116 & 177 & -1.12 & .265 & -3963 & -4007 & 171 & 0.24 & .809 \\
\hline MGA Latency & 722 & 735 & 18.0 & -0.16 & .871 & 614 & 555 & 19.3 & 1.40 & .163 & 652 & 670 & 19.0 & -0.08 & .940 \\
\hline MGA & 84.3 & 86.0 & 1.32 & -1.36 & .183 & 89.3 & 88.1 & 1.41 & 0.63 & .533 & 81.2 & 80.8 & 1.36 & 0.75 & .458 \\
\hline
\end{tabular}


Table 3. Mean and statistics regarding the weight effect in the Displace phase and for the movement time for a known or unknown weight. P-values are in bold when significant. All the latencies are expressed in $\mathrm{ms}$, the acceleration and deceleration peaks in $\mathrm{mm} / \mathrm{s}^{2}$, the velocity in mm/s, the MGA (Maximum Grip Aperture) in mm, and the movement time in ms.

\begin{tabular}{|c|c|c|c|c|c|c|c|c|c|c|c|c|c|c|c|}
\hline KNOWN & \multicolumn{5}{|c|}{ Weight } & \multicolumn{5}{|c|}{ Weight } & \multicolumn{5}{|c|}{ Weight } \\
\hline & \multicolumn{5}{|c|}{$5 / 6$} & \multicolumn{5}{|c|}{$7 / 8$} & \multicolumn{5}{|c|}{$9 / 10$} \\
\hline Displace Phase & Light & Heavy & $\mathrm{SE}$ & $\mathrm{t}$ & $p$ & Light & Heavy & $\mathrm{SE}$ & $\mathrm{t}$ & $p$ & Light & Heavy & SE & $\mathrm{t}$ & $p$ \\
\hline Acceleration Latency & 984 & 1113 & 30.3 & -4.23 & $<.001$ & 884 & 979 & 30.5 & -3.15 & .003 & 867 & 971 & 30.4 & -3.47 & .001 \\
\hline Acceleration Peak & 2887 & 2393 & 282 & 1.74 & .090 & 3185 & 2555 & 283 & 2.16 & .037 & 3286 & 2570 & 283 & 2.58 & .014 \\
\hline Velocity Latency & 1142 & 1251 & 28.7 & -3.70 & $<.001$ & 1007 & 1110 & 28.9 & -3.59 & $<.001$ & 999 & 1108 & 28.8 & -3.87 & $<.001$ \\
\hline Velocity Peak & 388 & 367 & 17.2 & 1.22 & .230 & 393 & 395 & 17.3 & -0.07 & .946 & 418 & 390 & 17.2 & 1.55 & .129 \\
\hline Deceleration Latency & 1239 & 1335 & 31.5 & -3.06 & .004 & 1128 & 1216 & 31.7 & -2.84 & .006 & 1110 & 1202 & 31.6 & -3.02 & .004 \\
\hline Deceleration Peak & -1147 & -1523 & 170 & 0.45 & .656 & -1407 & -1747 & 171 & 2.08 & .042 & -1630 & -1666 & 171 & 0.26 & .796 \\
\hline Height & 209 & 216 & 4.41 & -1.72 & .091 & 207 & 218 & 4.37 & -2.52 & .015 & 217 & 217 & 4.36 & -0.08 & .927 \\
\hline Movement time & 1743 & 1940 & 42.0 & -4.714 & $<.001$ & 1710 & 1824 & 42.2 & -2.704 & .009 & 1600 & 1760 & 42.1 & -3.807 & $<.001$ \\
\hline \multirow[t]{2}{*}{ UNKNOWN } & \multicolumn{5}{|c|}{ Weight } & \multicolumn{5}{|c|}{ Weight } & \multicolumn{5}{|c|}{ Weight } \\
\hline & \multicolumn{5}{|c|}{$5 / 6$} & \multicolumn{5}{|c|}{$7 / 8$} & \multicolumn{5}{|c|}{$9 / 10$} \\
\hline Displace Phase & Light & Heavy & $\mathrm{SE}$ & $\mathrm{t}$ & $p$ & Light & Heavy & $\mathrm{SE}$ & $\mathrm{t}$ & $p$ & Light & Heavy & SE & $\mathrm{t}$ & $p$ \\
\hline Acceleration Latency & 1074 & 1194 & 30.4 & -3.93 & $<.001$ & 902 & 1084 & 30.7 & -5.82 & $<.001$ & 899 & 1081 & 30.2 & -6.01 & $<.001$ \\
\hline Acceleration Peak & 3586 & 2152 & 282 & 5.08 & $<.001$ & 5625 & 2272 & 284 & 11.8 & $<.001$ & 5158 & 2391 & 281 & 9.82 & $<.001$ \\
\hline Velocity Latency & 1219 & 1370 & 28.8 & -5.22 & $<.001$ & 1019 & 1218 & 29.1 & -6.77 & $<.001$ & 1010 & 1207 & 28.6 & -6.88 & $<.001$ \\
\hline Velocity Peak & 442 & 342 & 17.2 & 5.81 & $<.001$ & 574 & 367 & 17.4 & 11.8 & $<.001$ & 525 & 368 & 17.1 & 9.15 & $<.001$ \\
\hline Deceleration Latency & 1309 & 1447 & 31.6 & -4.36 & $<.001$ & 1107 & 1283 & 31.9 & -5.47 & $<.001$ & 1086 & 1290 & 31.4 & -6.49 & $<.001$ \\
\hline Deceleration Peak & -1893 & -1445 & 170 & -2.61 & .011 & -3027 & -1542 & 172 & -8.60 & $<.001$ & -2755 & -1595 & 169 & -6.86 & $<.001$ \\
\hline Height & 240 & 220 & 4.38 & 4.69 & $<.001$ & 264 & 225 & 4.41 & 8.67 & $<.001$ & 248 & 212 & 4.33 & 8.34 & $<.001$ \\
\hline Movement time & 1874 & 2054 & 42.0 & -4.239 & $<.001$ & 1726 & 1950 & 42.6 & -5.233 & $<.001$ & 1722 & 1864 & 41.8 & -3.377 & .001 \\
\hline
\end{tabular}

